\title{
Perioperative management of facial bipartition surgery
}

This article was published in the following Dove Press journal:

Open Access Surgery

6 November 2015

Number of times this article has been viewed

\section{Marco Caruselli' \\ Michael Tsapis ${ }^{1,2}$ \\ Fabrice Ughetto \\ Gregoire Pech-Gourg ${ }^{3}$ \\ Dario Galante 4 \\ Olivier Paut ${ }^{\prime}$}

'Anesthesia and Intensive Care Unit, La Timone Children's Hospital, 2Pediatric Transport Team, SAMU 13, La Timone Hospital, ${ }^{3}$ Pediatric Neurosurgery Unit, La Timone Children's Hospital, Marseille, France; ${ }^{4}$ Anesthesia and Intensive Care Unit, University Hospital Ospedali Riuniti of Foggia, Foggia, Italy
Correspondence: Marco Caruselli Anesthesia and Intensive Care Unit, La Timone Children's Hospital, Boulevard Jean Moulin, Marseille, France Tel +33049|384944

Email m.caruselli@gmail.com
Abstract: Severe craniofacial malformations, such as Crouzon, Apert, Saethre-Chotzen, and Pfeiffer syndromes, are very rare conditions (one in 50,000/100,000 live births) that often require corrective surgery. Facial bipartition is the more radical corrective surgery. It is a high-risk intervention and needs complex perioperative management and a multidisciplinary approach. Keywords: craniofacial surgery, facial bipartition surgery, craniofacial malformations, pediatric anesthesia

\section{Introduction}

Severe craniofacial malformations, such as Crouzon, Apert, Saethre-Chotzen, and Pfeiffer syndromes, are very rare conditions (one in 50,000/100,000 live births) that often require corrective surgery. Indications for corrective surgery are either functional for compromised respiratory function, feeding difficulties, or visual deterioration, or to prevent future psychological disorders due to the very unusual appearance of these patients. ${ }^{1-3}$

Facial bipartition is the more radical corrective surgery and is often a long and difficult intervention requiring a multidisciplinary approach (neurosurgeons, maxillofacial surgeons, plastic surgeons, and anesthetists). This surgery, performed in combination with medial canthopexy, allows for hemifacial rotation toward the midline and correction of the position of the lateral canthi. Often the procedure is associated with a Le Fort I osteotomy. It is to be considered high-risk surgery because of potentially difficult intubation, massive intraoperative bleeding, and perioperative metabolic acidosis. ${ }^{4-6}$

Intubation is difficult because the craniofacial anatomical abnormalities sometimes limit mouth opening and the glottic view. Further, obstructive sleep apnea is often present. ${ }^{7}$ The massive intraoperative bleeding is typical of major craniofacial surgery, so it is necessary before starting the surgery to ensure an adequate reserve of blood products in the event of activation of a massive transfusion protocol. Perioperative metabolic acidosis is due to a combination of blood loss and electrolyte shifts following administration of large amounts of colloids, crystalloids, and blood products.

In this paper, we describe our recent perioperative experience of facial bipartition surgery in a 3-year-old child (weighing $13 \mathrm{~kg}$ ) who had an asymmetric craniofacial cleft with hypertelorism and ethmoid agenesis (Figure 1).

Monitoring included electrocardiography, pulse oximetry, invasive arterial pressure monitoring, temperature, end tidal carbon dioxide, and urine output. Induction of anesthesia was achieved by inhaled sevoflurane at a concentration of $6 \%$. After peripheral 


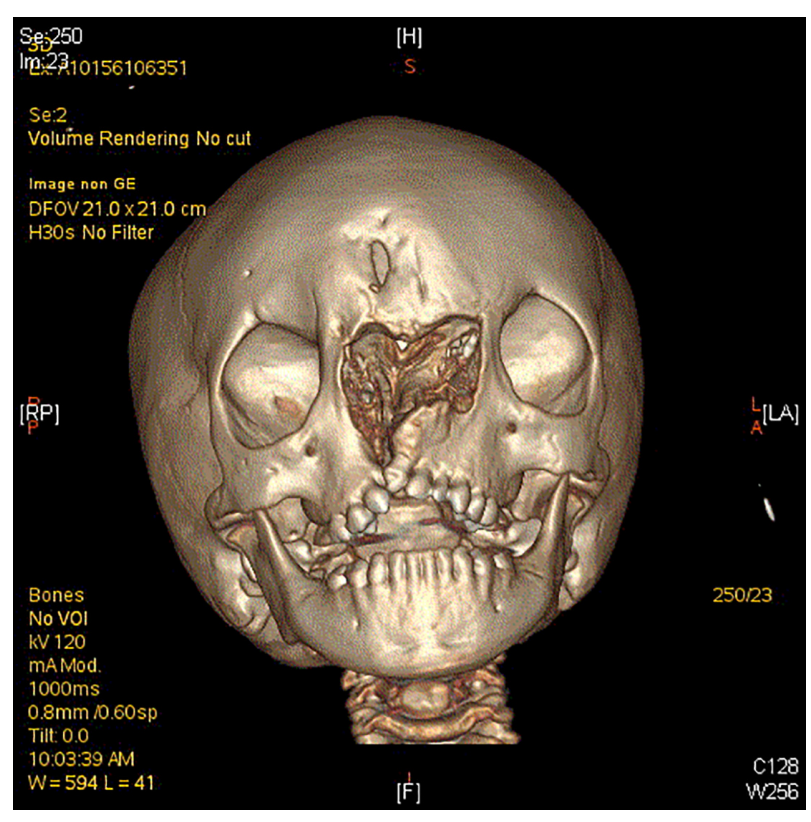

Figure I 3D reconstruction of the skull.

vein cannulation with a $22 \mathrm{G}$ catheter, intravenous propofol $4 \mathrm{mg} / \mathrm{kg}$ and remifentanil $0.2 \mu \mathrm{g} / \mathrm{kg} / \mathrm{min}$ were administered. The trachea was intubated with a $4.5 \mathrm{~mm}$ armored tube. The femoral artery and vein were cannulated with two 3 French catheters and another peripheral (saphenous) vein with an $18 \mathrm{G}$ intravenous catheter.

Before surgery, we started intravenous infusion of tranexamic acid at $10 \mathrm{mg} / \mathrm{kg} / \mathrm{h}$ during the first hour and $5 \mathrm{mg} / \mathrm{kg} / \mathrm{h}$ during the following hours. General anesthesia was maintained by inhaled sevoflurane (minimum alveolar concentration 1.0) and continuous infusion of remifentanil $(0.1-0.4 \mu \mathrm{g} / \mathrm{kg} / \mathrm{min})$. Intraoperative antibiotic prophylaxis with amoxicillin/clavulanic acid (50 mg/kg of amoxicillin) was administered.

The initial hemoglobin level was $11.5 \mathrm{~g} / \mathrm{dL}$, and decreased during the hemorrhagic phases (particularly during frontal bone dissection) to $7.5 \mathrm{~g} / \mathrm{dL}$. Therefore, $280 \mathrm{~mL}$ of packed red blood cells and $115 \mathrm{~mL}$ of Cell Saver were transfused to achieve a hemoglobin level of $12.5 \mathrm{~g} / \mathrm{dL}$. The remifentanil infusion rate varied between 0.1 and $0.4 \mu \mathrm{g} / \mathrm{kg} / \mathrm{min}$ according to the phase of the surgery. The total fluid infusion was $1,500 \mathrm{~mL}$ (including $250 \mathrm{~mL}$ of $4 \%$ albumin) during 9 hours of anesthesia ( 8 hours of surgery). The total urine output was $225 \mathrm{~mL}(1.92 \mathrm{~mL} / \mathrm{kg} / \mathrm{h})$.

After surgery, the patient was kept sedated and mechanically ventilated to prevent postoperative respiratory failure due to nasopharyngeal and facial swelling. Corticosteroid therapy (methylprednisolone $1 \mathrm{mg} / \mathrm{kg}$ /day) was also administered to prevent this problem. The patient was extubated on the fourth day after surgery and transferred on the following day to the pediatric surgery ward. A significant aesthetic and functional improvement occurred after surgery. The functional improvement was acquisition of binocular vision that, because of hypertelorism, was impossible before surgery. For adaptation, the patient is followed in the orthoptic service. The patient will undergo a second surgery in the coming months to improve the shape of the nose.

\section{Discussion}

Facial bipartition is a high-risk corrective surgery, which requires a complex multidisciplinary approach. The anesthetist has to expect two types of difficulty during perioperative management. The first problem is the potentially difficult intubation, which occurs due to the abnormal craniofacial anatomy. Various devices have been utilized, including the Airtraq, Bonfils fiberscope, and traditional fiberscope. ${ }^{8-10}$ The Bonfils and the traditional fiberscope require specific expertise; but their advantage is that it is possible to intubate even with limited mouth opening. On the other hand, the Airtraq can be used successfully without specific expertise, but it is not usable with limited mouth opening. The second problem is the risk of massive bleeding, particularly during frontal bone dissection, so it is necessary to maintain continuous blood pressure monitoring by arterial cannulation, an adequate reserve of blood products, and continuous infusion of antihemorrhagic drugs, such as tranexamic acid. Use of tranexamic acid in pediatric patients for bleeding during high-risk surgery is reported by many authors. ${ }^{11-13}$ For postoperative management, it is advisable to extubate the patient after adequate corticosteroid therapy and preventive fibroscopic airway control to check for residual edema. Use of corticosteroids can have an immunosuppressant effect, but prevention of postoperative massive facial edema justifies their use.

Sometimes, fronto-orbital advancement or frontal sinus cranialization surgery can be complicated postoperatively by an extradural dead space because of expansion of the prefrontal subarachnoid space. ${ }^{14,15}$ This complication did not occur in our patient.

These patients often have obstructive sleep apnea and a high incidence of perioperative respiratory complications, particularly bronchospasm. The bronchospasm is caused by profuse secretions that may cause wheezing and contribute to an increase in airway irritability. Elwood et al have reported on 145 anesthetics administered to 18 individuals with Apert syndrome and 15 with perioperative wheezing; in four cases, surgery was cancelled because of intractable 
wheezing. ${ }^{16}$ Further, reintubation in patients with massive facial swelling and airway edema can be very difficult. In our case, 4 days of therapy and mechanical ventilation were required before extubation.

\section{Conclusion}

Facial bipartition is a high-risk intervention and involves complex perioperative management. It is necessary to have adequate resources in the event of difficult intubation and to avoid potentially fatal intraoperative hemorrhage.

\section{Acknowledgment}

We thank our anesthesia nurse specialists, Hélène Larrede and Murielle Giraud, for their invaluable help with management of anesthesia. Institutional review board approval was deemed not necessary for this retrospective case report. All principles outlined in the Declaration of Helsinki were followed. Informed consent was obtained for this publication.

\section{Disclosure}

The authors report no conflicts of interest in this work.

\section{References}

1. Driessen C, Joosten KF, Bannink N, et al. How does obstructive sleep apnoea evolve in syndromic craniosynostosis? A prospective cohort study. Arch Dis Child. 2013;98:538-543.

2. Miller CK. Feeding issues and interventions in infants and children with clefts and craniofacial syndromes. Semin Speech Lang. 2011;32: $115-126$.

3. van. der Vlugt JJ, van der Meulen JJ, Creemers HE, Willemse SP, Lequin ML, Okkerse JM. The risk of psychopathology in children with craniosynostosis. Plast Reconstr Surg. 2009;124:2054-2060.
4. Perkins JA, Sie KC, Milczuk H, Richardson MA. Airway management in children with craniofacial anomalies. Cleft Palate Craniofac J. 1997;34: 135-140.

5. Pietrini D. Intraoperative management of blood loss during craniosynostosis surgery. Paediatr Anaesth. 2013;23:278-280.

6. Choi AY, Ahmad NS, de Beer DA. Metabolic changes during major craniofacial surgery. Paediatr Anaesth. 2010;20:851-855.

7. Barnett S, Moloney C, Bingham R. Perioperative complications in children with Apert syndrome: a review of 509 anesthetics. Paediatr Anaesth. 2011;21:72-77.

8. Sbaraglia F, Lorusso R, Garra R, Sammartino M. Usefulness of Airtraq in a 3-month-old child with Apert syndrome. Paediatr Anaesth. 2011;21:984-985.

9. Caruselli M, Giretti R, Pallotto R, Rocchi G, Carboni L. Intubation using a "Bonfils fiberscope" in a patient with Pfeiffer syndrome. J Bronchology Interv Pulmonol. 2011;18:374-375.

10. Wheeler M, Roth AG, Dsida RM, et al. Teaching residents pediatric fiberoptic intubation of the trachea: traditional fiberscope with an eyepiece versus a video-assisted technique using a fiberscope with an integrated camera. Anesthesiology. 2004;101:842-846.

11. Newton PO, Bastrom TP, Emans JB, et al. Antifibrinolytic agents reduce blood loss during pediatric vertebral column resection procedures. Spine. 2012;37:1459-1463.

12. Song G, Yang P, Zhu S, et al. Tranexamic acid reducing blood transfusion in children undergoing craniosynostosis surgery. J Craniofac Surg. 2013;24:299-303.

13. Grassin-Delyle S, Couturier R, Abe E, Alvarez JC, Devillier P, Urien S. A practical tranexamic acid dosing scheme based on population pharmacokinetics in children undergoing cardiac surgery. Anesthesiology. 2013;118:853-862.

14. Spinelli HM, Irizarry D, McCarty JG, Cutting CB, Noz ME. An analysis of extradural dead space after fronto-orbital surgery. Plast Reconstr Surg. 1994;7:1372-1377.

15. Moore MH, Abbott AH. Extradural deadspace after infant frontoorbital advancement in Apert syndrome. Cleft Palate Craniofac J. 1996;3:202-205.

16. Elwood T, Sarathy PV, Geiduschek JM, Ulma GA, Karl HW. Respiratory complications during anaesthesia in Apert syndrome. Paediatr Anaesth. 2001;11:701-703.
Open Access Surgery

\section{Publish your work in this journal}

Open Access Surgery is an international, peer-reviewed, open access journal that focuses on all aspects of surgical procedures and interventions. Patient care around the peri-operative period and patient outcomes post surgery are key topics. All grades of surgery from minor cosmetic interventions to major surgical procedures are covered. Novel techniques

\section{Dovepress}

and the utilization of new instruments and materials, including implants and prostheses that optimize outcomes constitute major areas of interest. The manuscript management system is completely online and includes a very quick and fair peer-review system. Visit http://www.dovepress.com/ testimonials.php to read real quotes from published authors. 